\title{
WILLINGNESS OF PROFESSIONALS WORKING IN SPECIALIZED HOSPITALS AND SOCIAL SERVICES TO WORK WITH PATIENTS AND CONSUMERS SUFFERING FROM MENTAL ILLNESSES

\author{
Daniela Konstantinova Draganova ${ }^{1}$, Nikolina Stancheva Angelova-Barbolova ${ }^{2}$
}

\begin{abstract}
At the current level of development in psychiatry, in the conditions of deinstitutionalization of mental health services and increased opportunities for control of the symptoms of mental disorders, the problem related to the socialization of patients is becoming more and more relevant. More than $50 \%$ of patients with schizophrenia are in a socially active age, which gives rise to the social significance of their rehabilitation.

International practice shows that all specialists dealing with the rehabilitation of patients with mental disorders need to undergo training, which includes the adoption of special methods and techniques. Their work is complex, long and creative.

In Bulgaria there are many national strategies that present different programs for long-term care or only analyze the current situation and care needs. There is no clear vision of how exactly in the future and with what means and specialists this process will take place. The development of psychiatric care lags far behind the needs of the population. There is a serious risk that the lack of trained specialists can ruin the good intentions for deinstitutionalization.

The goal of the present study is to examine the readiness of specialists working in specialized medical institutions and social services to work with patients and users suffering from mental illness.
\end{abstract}

A survey method was used among specialists from medical institutions and social services for patients with mental and behavioral disorders.

Most of the specialists in psychiatric hospitals in Bulgaria feel prepared to work with the mentally ill - 88.9\%;

Almost everyone believes that they need additional training.

UDC Classification: 614.39, DOI: https://doi.org/10.12955/pmp.v2.164

Keywords: Specialists; Mentally ill; medical institutions, social services

\section{Introduction}

Providing medical and social care for patients with schizophrenia with an unfavourable course of illness, severe negative symptoms, difficult adaptation in society, limited employment and independent living is one of the main activities in providing long-term care to psychiatric patients. The quality of life of these patients in all countries remains extremely low (Priebe et al., 1998; Chadzynka et al., 2003). They quickly lose social connections and contacts with relatives, self-care skills. Those deprived of social assistance often fall to the "bottom" of society without means of subsistence, filling the ranks of the unemployed and homeless (Allison et al., 2003).

The Assertive community treatment approach is one of the most widely studied approaches in psychiatric rehabilitation.

The only way by which modern societies deal with this problem is deinstitutionalization - transformation of psychiatric hospitals to a small number of short-term accommodation for acute cases and outsourcing services to patients and families in the community by developing a network of daycare centers for psychosocial rehabilitation, sheltered housing with nonstop medical and other social services. Today there is a broad consensus on the need to shift from the model of care based on traditional large psychiatric institutions to modern comprehensive community care models (Mueser \& Berenbaum, 1990). The main reason for this change is that access to mental health care for people with long-term mental disorders is much better done with community services than traditional psychiatric hospitals. Services in the community are related to greater customer satisfaction and more satisfying everyday needs.

They also implement better the principles of continuity of care and greater flexibility of services, which makes it possible for the identification and frequent treatment of early relapses as well as increase adherence to treatment.

However, despite strong arguments, there is still much to be done if we are to provide affordable, effective, high quality and long-term mental health care for all people with severe mental illness.

Of great importance is the training of specialists in the multidisciplinary team to provide care for patients (Mueser et al., 1990).

\footnotetext{
${ }^{1}$ Angel Kanchev University of Ruse, Ruse, Bulgaria, ddraganova@uni-ruse.bg

${ }^{2}$ Angel Kanchev University of Ruse, Ruse, Bulgaria, nangelova@uni-ruse.bg
} 
In Bulgaria, the development of psychiatric care lags far behind the needs of the population.

Psychosocial rehabilitation programs for people with severe mental disorders still do not have a good position everywhere in the country.

International practice shows that all specialists dealing with the rehabilitation of patients with mental disorders need to undergo training, which includes using of special methods and techniques.

Their work is complex, continuous and creative according to Thornicroft and Tansella (2003), which is based on the following principles: Optimism about achieving results; Confidence in the fact that even small improvements can lead to positive change and enhance the quality of life of the patient; Belief that the motivation of the patient to change their situation may occur not so much because of the special rehabilitative events, but also with his own efforts;

According to Melekhov (1992) and Volovik (1985) the distortions and shortcomings in the social functioning of the patient at any time are determined by the interaction of three groups of factors. The first group of factors considers the path dynamics - the importance of productive symptoms, the expression of negativity, the rate of progression. The second group of factors are psychological and their influence refers to the level of development, level of self-esteem, nature of social perceptions, habits of productive behavior. The third group of factors considers the social environment.

In their analysis of 35 studies, Dion and Anthony (1987) found that psychiatric rehabilitation reduces re-hospitalizations, positively affect employment, skills development, customer satisfaction and the amount of time spent in the community. Reducing the use of hospital treatment after the inclusion of the subject in psychiatric rehabilitation programs and / or case management is well documented and is a sustainable finding in many studies (Dincin \& Witheridge, 1982).

In Bulgaria there are no work and financial plans provided for continuity and complexity of care multidisciplinary teams; coordinator of care - leading the case; establishing a system of services for people with a serious mental illness and severe social dysfunction with which to ensure the unity of the care and social inclusion and to ensure their own safety and the public safety.

\section{Material and Methods}

Goal

The goal of this study is to investigate the willingness of professionals working in specialized hospitals and social services to work with patients and consumers suffering from mental illnesses.

The object of the study is staff with different specialties from medical institutions and social services at Mental Health Centers and psychiatric hospitals.

\section{Methods}

A sociological method was used through an anonymous survey among specialists from psychiatric hospitals who agreed to participate in the study. It was conducted in the period of April 2014 - June 2014. Each participant was explained the purpose of the survey and how to fill in and return the questionnaire. Participation in the survey was voluntary and anonymous in order to obtain the most reliable information on the questions asked. The questionnaire is specially developed for the purposes of this study. It contains a total of 18 questions, 16 of which have standardized answers and 2 openended questions for free expression of opinion.

A documentary method was employed for studying normative documents - strategies, laws and methodological guidelines related to the provision of health and social services to patients with mental illness, measures to improve the mental health of the nation; structure and activity of social services in the community for the mentally ill.

Mathematical and statistical methods are used to process and analyze the results of the study. The data processing is performed with a package for processing SPSS 16.0.

\section{Results}

According to the WHO report, the activities to improve the quality of care in psychiatric hospitals and deinstitutionalization continue to be very important in countries where psychiatric hospitals are still responsible for a significant part of the care for people with severe mental disorders, such as Bulgaria.

The study was conducted among 154 specialists from Centers for Mental Health (75.3\%) and Social Services $(24.7 \%)$ for Patients with Mental Disabilities in Ruse, Dobrich and Veliko Tarnovo. 
Their professions are psychologist (7.1\%), psychiatrist (11\%), social worker $(5.1 \%)$, pedagogues, music therapists, art therapists, occupational therapists (6.1\%) and nurses (70.7)\%.

Among respondents dominate women $-88.3 \%$ due to the feminisation of professions working in medical institutions.

The age of respondents specialists has the following distribution:

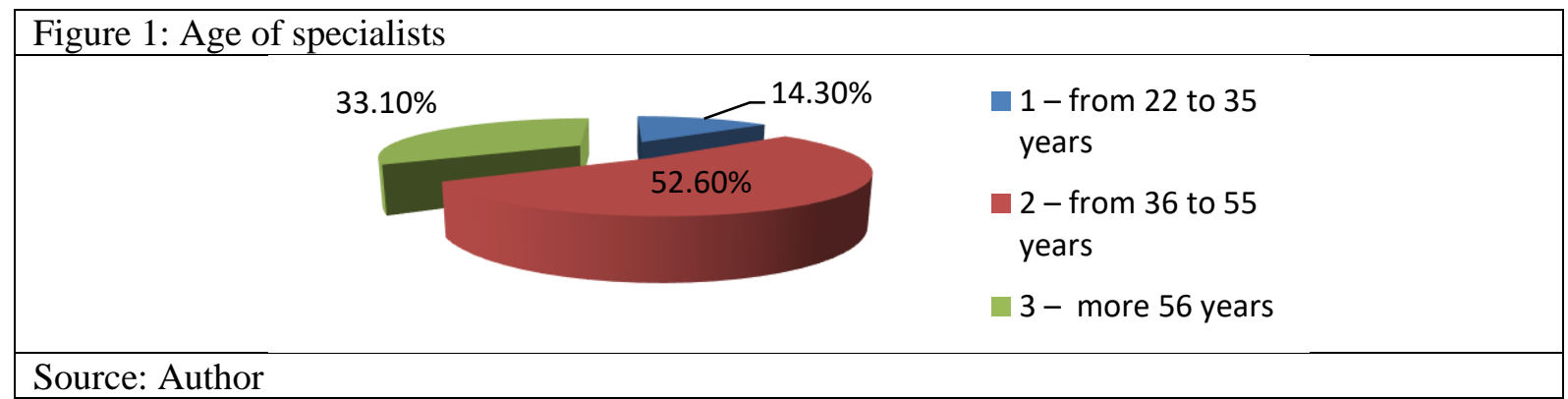

Most of them have extensive experience in medical institutions for the mentally ill, as shown in the following table.

\begin{tabular}{|l|l|}
\hline Table 1: Years working with people with mental illness \\
\hline \multicolumn{5}{|l|}{ How many years have you been working with people with mental illness? } & $\%$ \\
\cline { 2 - 3 } 1 -up to 5 years & $27.9 \%$ \\
\hline 2 -from 5 to 10 years & $16.9 \%$ \\
\hline 3 - from 10 to 15 years & $15.6 \%$ \\
\hline 4- more than 15 years & $39.6 \%$ \\
\hline Source: Author & \\
\hline
\end{tabular}

This fact, along with strong life experience suggests a well-trained and qualified staff.

The question "Do you feel prepared to work with mentally ill?" $88.9 \%$ answered "yes"; $9.8 \%$ "no" and $5.2 \%$ "I can not say." Despite these facts, experts have felt that there is a need for additional training in working with the mentally ill.

\begin{tabular}{|l|l|}
\hline \multicolumn{1}{|c|}{ Table 2: The need for additional training } & \multicolumn{1}{|c|}{ Do you need additional training to work with the mentally ill? } \\
\hline 1 - yes & 85.0 \\
\hline 2 - no & 9.8 \\
\hline 3 - I can not say & 5.2 \\
\hline Source: Author
\end{tabular}

When checking with the non-parametric test of Wilcoxon, a Asymp. Sig. (Two-tailed) $=0.000 /$ at risk of error $\alpha=0.05 /$ dependence is found between specialty and the expressed opinion of the need for additional training for working with mentally ill patients. This result is observed in psychologists, psychiatrists, social workers and other staff, referred to in equal parts as educator and medical paramedic. In nurses, a statistical significance can be found in correlation respectively $0.006<\alpha=0.05$; Dependence was not studied in subjects such as art therapist, music therapist and ergotherapist as the defined professions are too small percentage - less than 5\%, which does not allow us to look for dependance according to statistical significance.

The training they think they need is mainly related to condition assessment (74.3\%), reaction to aggressive patients $(9.8 \%)$, case management $(7.2 \%)$, psychosocial rehabilitation of mentally ill patients $(8.7 \%)$, other responses $(2.1 \%)$.

Interest for the study also presents assessing the specialists for their willingness to evaluate the status of the mentally ill.

\begin{tabular}{|l|l|}
\hline \multicolumn{1}{|c|}{ Table 3: Ready to evaluate the status of the mentally ill } \\
\hline \multicolumn{1}{|c|}{ Are you ready to assess the status of the mentally ill? } & $\%$ \\
\hline 1 - yes & $64.7 \%$ \\
\hline 2 - no & $10.7 \%$ \\
\hline 3 - I can not say & $24.6 \%$ \\
\hline Source: Author
\end{tabular}


The encountered difficulties are various. Only $19.1 \%$ of professionals responded that they are not sufficiently prepared, unanswered are $49.2 \%$ and $6.1 \%$ answer the question with "I do not know." The remaining 5.2\% answered that it is not common for the doctor to ask for their assessment; lack of such practice; nobody is interested in their assessment; no difficulty - 7.6\%; unequal distribution of patients; imposed authoritarian solutions; problem in cooperation with other professionals; lack of information for the rights of medical specialist; lack of policy by the Ministry of Health regarding the mentally ill; huge paperwork.

\section{Conclusions:}

Several conclusions can be drawn from the research:

The majority of specialists in psychiatric hospitals in Bulgaria feel prepared to work with mentally ill $88.9 \%$. This is probably due to the fact that $55.2 \%$ of the surveyed persons have over 10 years of experience in working with patients with mental and behavioral disorders.

Despite the accumulated professional experience, almost all believe that they have a need for additional training - 85.0\%

Willingness to evaluate the status of the mentally ill is expressed from just some of the professionals $64.7 \%$, which is insufficient to provide quality care.

It is necessary to take measures for legal regulation by the Ministry of Health regarding the rights, obligations and competencies of each specialist in the team for the treatment and psychosocial rehabilitation of the mentally ill.

\section{References}

Allison D., Mackell J., Donnell D. The Impact of Weight Gain on Quality of Life Among Persons With Schizophrenia Psychiatric Services. (2003). - V. 54.-P. 565-567. Retrieved from

https://ps.psychiatryonline.org/doi/full/10.1176/appi.ps.54.4.565

Chadzyńska M, Spiridonow K, Kasperek B, Meder J. (2003). Porównanie jakości zycia osób chorych na schizofrenie i ich opiekunów [Quality of life of schizophrenic patients and their caregivers--comparison]. Psychiatr Pol. 2003 NovDec;37(6):1025-36. Polish. PMID: 14727374.

Dincin J, Witheridge TF. (1982). Psychiatric rehabilitation as a deterrent to recidivism. Hosp Community Psychiatry. 1982 Aug;33(8):645-50. doi: 10.1176/ps.33.8.645. PMID: 7118100.

Dion G., Anthony W. (1987). Research in psychiatric rehabilitation: A review of experimental and quasi-experimental studies // Rehabilitation Counselling Bull. 1987. - V. 30. - P. 177-203.

Health Act (2004), State Gazette 70, 145-165, Bg (Zakon za zdraveto (2004), DV 70, 145-165, Bg)

Mueser, K.T., Berenbaum, H. (1990). Psychodynamic treatment of schizophrenia. Is there a future? [Editorial] Psychological Medicine, 20:253-262, Retrieved from DOI:https://doi.org/10.1017/S003329170001758X

https://www.cambridge.org/core/journals/psychological-medicine/issue/54D25B245B8F262C2FA827CBD93DCAA1

National Program for Mental Health of the Citizens of the Republic of Bulgaria 2017 - 2023 (Nacionalna programa za psihichno zdrave na gragdanite na Republika Bulgaria 2017-2023 godina)

Priebe, S., Warner, R., Hubschmid, T., \& Eckle, I. (1998). Employment, attitudes toward work, and quality of life among people with schizophrenia in three countries. Schizophrenia bulletin, 24(3), 469-477. Retrieved from https://doi.org/10.1093/oxfordjournals.schbul.a033341

Thornicroft G, Tansella M (2003) What are the arguments for community-based mental health care? Copenhagen, WHO Regional Office for Europe (Health Evidence Network report; Retrieved from http://www.euro.who.int/document/E82976.pdf, accessed 29 August 2003).

Volovik, V.M., O funkcionalnoi diagnostike psichischeskich zabolevanii, Novoe v teorii I praktike reabilitaciipsichischeki bolnih, 1985. - S.26-31. [About functional diagnostics of mental diseases, New in theory and practice of rehabilitation of mentally ill., 1985. - P.26-31] Retrieved from https://www.dissercat.com/content/psikhosotsialnaya-reabilitatsiya-bolnykhshizofreniei-na-otdalennykh-etapakh-techeniya-zabol 